\title{
The anti-metastatic effects of the phytoestrogen arctigenin on human breast cancer cell lines regardless of the status of ER expression
}

\author{
THRESSI MAXWELL, SO-YOUNG CHUN, KYU-SHIK LEE, SOYOUNG KIM and KYUNG-SOO NAM \\ Department of Pharmacology and Intractable Disease Research Center, School of Medicine, \\ Dongguk University, Gyeongju-si 780-350, Republic of Korea
}

Received August 8, 2016; Accepted December 12, 2016

DOI: $10.3892 /$ ijo.2016.3825

\begin{abstract}
Arctigenin is a plant lignan extracted from Arctium lappa that has been shown to have estrogenic properties. In spite of the health benefits of phytoestrogens reducing the risk of osteoporosis, heart disease, and menopausal symptoms, its benefits against the risk of breast cancer have not been fully elucidated. Thus, we investigated the effects of arctigenin on metastasis of breast cancer using both estrogen receptor (ER)-positive MCF-7 and ER-negative MDA-MB-231 human breast cancer cell lines to see if the effects are dependent on the status of ER expression. In ER-positive MCF-7 cells, arctigenin efficiently inhibited 12- $O$-tetradecanoylphorbol13-acetate (TPA)-induced cell migration and invasion. The activity of crucial metastatic protease matrix metalloprotease (MMP)-9 in gelatin zymography was also efficiently decreased by arctigenin, as well as its mRNA expression. Notably, arctigenin exhibited similar anti-metastatic effects even in ER-negative MDA-MB-231 cells, suggesting that the anti-metastatic effects of arctigenin were not exerted via the ER. The upstream signaling pathways involved in the regulation of MMP-9 and urokinase plasminogen activator (uPA)
\end{abstract}

Correspondence to: Dr Kyung-Soo Nam or Dr Soyoung Kim, Department of Pharmacology and Intractable Disease Research Center, School of Medicine, Dongguk University, 123 Dongdae-ro, Gyeongju-si 780-350, Republic of Korea

E-mail:namks@dongguk.ac.kr

E-mail: soyoungkim@dongguk.ac.kr

Abbreviations: ER, estrogen receptor; RT-PCR, reverse transcriptase-polymerase chain reaction; TPA, 12- $O$-tetradecanoylphorbol-13-acetate; MMP, matrix metalloprotease; TIMP, tissue inhibitor of metalloprotease; uPA, urokinase plasminogen activator; uPAR, urokinase plasminogen activator receptor; Akt, protein kinase B; NF- $\kappa \mathrm{B}$, nuclear factor kappa B; MAPK, mitogen-activated protein kinase; ERK, extracellular signal-regulated kinase; JNK, c-Jun N-terminal kinase; AP-1, activator protein-1; PKC, protein kinase C; GAPDH, glyceraldehyde-3-phosphate dehydrogenase

Key words: arctigenin, phytoestrogen, metastasis, estrogen receptor, MCF-7 and MDA-MB-231 human breast cancer cells were analyzed using western blotting. The activation of Akt, NF- $\kappa$ B and MAPK (ERK $1 / 2$ and JNK 1/2) was found to be inhibited. Taken together, these data suggest that arctigenin confers anti-metastatic effects by inhibiting MMP-9 and uPA via the Akt, NF- $\kappa \mathrm{B}$ and MAPK signaling pathways on breast cancer, regardless of ER expression. Therefore, we propose that the intake of arctigenin could be an effective supplement for breast cancer patients.

\section{Introduction}

Arctigenin is a phenylpropanoid dibenzyl butyrolactone lignan (Fig. 1) found in members of the Asteraceae family eg: Arctium lappa (1). Arctium lappa, commonly known as burdock, and its extracts have long been consumed in Europe, North America and Asia. It is also traditionally used in folk medicine for treating sore throat and various infections. Several studies have shown that arctigenin possesses therapeutic effects for anti-viral (2-4), anti-inflammatory $(5,6)$, immune modulatory (7-10) and antitumor activities. Particularly, the antitumor activity of arctigenin has drawn much scientific interest and it has been tested in various human cancer cell lines, showing promising results in cancer cells of the stomach $(11,12)$, liver $(12)$, pancreas $(13,14)$, intestine $(15-17)$, lung $(12,18,19)$, bladder (20) and ovaries (21). Regarding the effects of arctigenin in breast cancers, Hsieh et al (22) showed that arctigenin markedly inhibited the growth of ER-negative MDA-MB-231 cells by triggering the mitochondrial caspase-independent apoptotic pathway. However, as lignans have been identified as phytoestrogens, arctigenin has also been reported to have estrogenic properties (23), making it an interesting candidate as breast and other hormone responsive cancer treatments.

When breast cancers express estrogen receptors, estrogen is considered to promote tumor growth. Since phytoestrogens are plant-derived chemicals that are structurally and/or functionally similar to estrogen, the role of phytoestrogens in breast cancer therapy is a highly debated topic $(24,25)$. Although their affinities to estrogen receptors are lower than that of estrogen, it is still of concern that a high intake of phytoestrogen may promote estrogen-dependent transcription, leading to increased risk in breast cancer patients, especially those treated with hormone therapy to reduce estrogen effects 


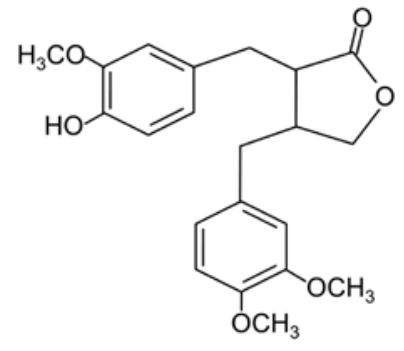

Figure 1. Chemical structure of arctigenin $(3 R, 4 R)-4-[(3,4-$ dimethoxyphenyl $)$ methyl]-3-[(4-hydroxy-3-methoxyphenyl)methyl]-2-tetrahydrofuranone.

within the breast tissue. However, there is growing evidence that phytoestrogens have a protective effect on the initiation of breast cancers by inhibiting the enzymes involved in the synthesis of estrogen, resulting in the reduced production of estrogen (26-28). Moreover, the low rates of breast cancer in Asia imply the health benefit of soy phytoestrogen, which is abundant in traditional Asian diet, in reducing the risk of breast cancer. Thus, it is still questionable whether phytoestrogens have beneficial effects against the risk of breast cancers, and determine the necessity for breast cancer patients to increase the intake of arctigenin or arctigenin-enriched foods.

Despite the successful treatment of the primary tumor, metastasis is a major cause of lethality in cancer patients. It was reported that $30-75 \%$ of patients undergoing surgery and adjuvant treatment developed recurrent metastatic disease and the median survival of patients with metastatic breast cancer is approximately 2 years $(29,30)$. Zhang et al (15) reported that arctigenin inhibited HCT116 colon cancer cell migration and invasion through the regulation of the H1F4A and $\mathrm{Wnt} / \beta$ catenin pathways. However, to the best of our knowledge, the anti-metastatic effect of arctigenin has not been clearly evaluated on breast cancer cells to date. In this study, we assessed the anti-metastatic effects of arctigenin on breast cancer cells. In order to check if the effects of the phytoestrogen arctigenin depended on the status of ER expression we employed both estrogen receptor (ER)-positive MCF-7 and ER-negative MDA-MB-231 human breast cancer cell lines.

\section{Materials and methods}

Cell culture. MCF-7 and MDA-MB-231 human breast cancer cell lines were purchased from the Korean Cell Line Bank (Seoul, Korea). MCF-7 cells were cultured in Dulbecco's modified Eagle's medium (DMEM) supplemented with $10 \%$ fetal bovine serum (FBS) and $10 \mu \mathrm{g} / \mathrm{ml}$ insulin (all from Welgene Inc., Daegu, Korea). MDA-MB-231 cells were cultured in DMEM supplemented with $10 \%$ FBS only. All media also contained $1 \%$ antibiotic-antimycotic solution (Welgene).

Wound healing assay. The cells were seeded in 6-well plates coated with collagen type I (Corning Life Sciences, Bedford, MA, USA) and grown to reach $100 \%$ confluence. The monolayers of cells were scratched with a $200 \mu \mathrm{l}$ pipette tip to create a wound. The cells were then treated with conditioned media containing $0,10,50$ and $200 \mu \mathrm{M}$ arctigenin (Santa Cruz Biotechnology, Inc., Santa Cruz, CA, USA). A total of $100 \mathrm{nM}$ 12-O-tetradecanoylphorbol-13-acetate (TPA; Sigma-Aldrich,
St. Louis, MO, USA) was used to induce cell migration in MCF-7 cells, while the treatment of TPA was omitted in MDA-MB-231 cells due to their inherent invasive properties. Two independent experiments were done in duplicate wells and optical microscopic images were captured from two different areas of each well at 0 and $24 \mathrm{~h}$. The area between the wound edges was measured at each time-point using ImageJ software as described before (31). Wound closure was quantified as previously described (32).

Matrigel invasion assay. The effect of arctigenin on the invasiveness of human breast cancer cells were determined using Matrigel and Transwell chambers (Corning Life Sciences) with $8.0-\mu \mathrm{m}$ pore polycarbonate filter inserts in 24 -well plates. The lower face of the polycarbonate filter (Transwell insert) was coated with Matrigel for $1 \mathrm{~h}$ at $37^{\circ} \mathrm{C}$. After coating, $3 \times 10^{4}$ cells were seeded into the Transwell chamber and $750 \mu \mathrm{l}$ culture media was added to the lower chamber. After $24 \mathrm{~h}$, cells were treated with conditioned media containing $2 \%$ FBS and 0 , 10, 50 and $200 \mu \mathrm{M}$ arctigenin (Santa Cruz Biotechnology). TPA (100 nM) was used to induce only MCF-7 cells and not the innately invasive MDA-MB-231 cells. The media in the bottom chamber was also changed to media containing $10 \%$ FBS and incubated at $37^{\circ} \mathrm{C}$ in $5 \% \mathrm{CO}_{2}$ atmosphere for $24 \mathrm{~h}$. Cells that migrated across the membrane were then fixed and stained using hematoxylin and eosin (H\&E) staining and photographed under an inverted microscope using x200 magnification.

Protein extraction and western blot analysis. The cells were treated with conditioned media containing $0,10,25,50,100$ and $200 \mu \mathrm{M}$ arctigenin for $24 \mathrm{~h}$. For induction of invasive characteristics, $100 \mathrm{nM}$ TPA was added for $1 \mathrm{~h}$ and then cells were harvested for protein extraction. The cells were lysed with RIPA buffer (50 mM Tris- $\mathrm{HCl} \mathrm{pH} 7.5$ with $150 \mathrm{mM} \mathrm{NaCl}, 1 \%$ Triton X-100, $1 \%$ sodium deoxycholate, $0.1 \%$ sodium dodecyl sulphate-SDS and $2 \mathrm{mM}$ EDTA) containing phosphatase and protease inhibitor cocktail (GenDEPOT, Barker, TX, USA). Lysates were cleared of debris at $13,000 \mathrm{rpm}$ for $20 \mathrm{~min}$ at $4^{\circ} \mathrm{C}$ and protein concentrations were determined using bicinchoninic acid reagent (BCA; Sigma-Aldrich). The proteins were separated by SDS-PAGE and transferred onto the polyvinylidene fluoride (PVDF) membranes at $100 \mathrm{~V}$ for $40 \mathrm{~min}$. The membranes were blocked in 5\% skim milk in Tris-buffered saline Tween-20 buffer (10 mM Tris- $\mathrm{HCl}, 150 \mathrm{mM} \mathrm{NaCl}$ and $0.1 \%$ Tween-20) for $1 \mathrm{~h}$ at room temperature. All primary antibodies were from Cell Signaling Technology (Beverly, MA, USA), were diluted 3,000 times and incubated with blots overnight at $4^{\circ} \mathrm{C}$ : phospho (\#4060) and total (\#4691) Akt, phospho (\#3033) and total (\#8242) NF-кB, phospho (\#4370) and total (\#4695) ERK1/2, phospho (\#4511) and total (\#8690) p38, phospho (\#4668) and total (\#9258) JNK 1/2,c-jun (\#9165), c-fos (\#2250) and GAPDH (\#5174). Corresponding HRP-conjugated secondary antibody (\#sc-2004; Santa Cruz Biotechnology) diluted 5,000 times was incubated with blots for $1 \mathrm{~h}$ at room temperature. The blots were developed and imaged using Luminescent Image Analyzer LAS-4000 (Fujifilm, Tokyo, Japan). Densitometric analysis was performed using Scion Image (Scion Corp., Frederick, MD, USA) with data from three independent experiments. 
Table I. Primer sequences and thermal cycling parameters used for RT-PCR.

PCR conditions (temperature and time)

\begin{tabular}{|c|c|c|c|c|}
\hline Gene & Primer sequence & Denaturation & Annealing & Extension \\
\hline \multirow[t]{2}{*}{ MMP-9 } & Forward: 5'-TTC ATC TTC CAA GGC CAA TC-3' & & & \\
\hline & Reverse: 5'-CTT GAC GCT GTC AAA GTT CG-3' & $94^{\circ} \mathrm{C}, 30 \mathrm{sec}$ & $55^{\circ} \mathrm{C}, 30 \mathrm{sec}$ & $72^{\circ} \mathrm{C}, 30 \mathrm{sec}$ \\
\hline \multirow[t]{2}{*}{$\mathrm{uPA}$} & Forward: 5'-CCA ATT AGG AAG TGT AAC AGC-3' & & & \\
\hline & Reverse: 5'-GCC AAG AAA GGG ACA TCT ATG-3' & $94^{\circ} \mathrm{C}, 30 \mathrm{sec}$ & $55^{\circ} \mathrm{C}, 30 \mathrm{sec}$ & $72^{\circ} \mathrm{C}, 45 \mathrm{sec}$ \\
\hline \multirow[t]{2}{*}{ uPAR } & Forward: 5'-CAT GCA GTG TAA GAC CAA CGG GGA-3' & & & \\
\hline & Reverse: 5'-AAT AGG TGA CAG CCC GGC CAG AGT-3' & $94^{\circ} \mathrm{C}, 30 \mathrm{sec}$ & $65^{\circ} \mathrm{C}, 30 \mathrm{sec}$ & $72^{\circ} \mathrm{C}, 45 \mathrm{sec}$ \\
\hline \multirow[t]{2}{*}{ GAPDH } & Forward: 5'-ATC CCA TCA CCA TCT TCC AG-3' & & & \\
\hline & Reverse: 5'-TTC TAG ACG GCA GGT CAG GT-3' & $94^{\circ} \mathrm{C}, 30 \mathrm{sec}$ & $58^{\circ} \mathrm{C}, 30 \mathrm{sec}$ & $72^{\circ} \mathrm{C}, 60 \mathrm{sec}$ \\
\hline \multirow[t]{2}{*}{ 18S rRNA } & Forward: 5'-GTA ACC CGT TGA ACC CCA TT-3' & & & \\
\hline & Reverse: 5'-CCA TCC AAT CGG TAG TAG CG-3' & $94^{\circ} \mathrm{C}, 30 \mathrm{sec}$ & $58^{\circ} \mathrm{C}, 30 \mathrm{sec}$ & $72^{\circ} \mathrm{C}, 30 \mathrm{sec}$ \\
\hline
\end{tabular}

Zymography. Conditioned media were collected and electrophoresed on $8 \%$ SDS-PAGE containing $0.1 \%$ (v/v) gelatin under non-reducing conditions. To remove SDS, the gel was washed with $2.5 \%$ Triton $\mathrm{X}-100$ for $1 \mathrm{~h}$ at room temperature. Gelatinase reaction was carried out at $37^{\circ} \mathrm{C}$ in reaction buffer (50 mM Tris- $\mathrm{HCl}, \mathrm{pH} 7.5,10 \mathrm{mM} \mathrm{CaCl}_{2}, 0.04 \% \mathrm{NaN}_{3}$ ) for $24 \mathrm{~h}$ in the case of MDA-MB-231 cells and $48 \mathrm{~h}$ in the case of MCF-7 cells. The gel was then stained with staining solution $(0.05 \%$ Coomassie brilliant blue in $45 \%$ methanol and $10 \%$ acetic acid) and destained with destaining solution $(10 \%$ methanol and $10 \%$ acetic acid). Proteolysis was detected as clear bands in a dark blue field. Densitometric analysis was performed using Scion Image with data from three independent experiments.

RNA isolation and reverse transcriptase polymerase chain reaction $(R T-P C R)$. The cells were treated with conditioned media containing $0,10,25,50,100$ and $200 \mu \mathrm{M}$ arctigenin and $100 \mathrm{nM}$ TPA for $24 \mathrm{~h}$. The cells were then harvested for RNA isolation. Total RNA was isolated using easy-BLUE ${ }^{\mathrm{TM}}$ Total RNA Extraction kit (iNtRON Biotechnology, Inc., Sungnam, Korea) and the RNA concentrations were determined using NanoDrop (Schimadzu Scientific Instruments, Columbia, MD, USA). The synthesis of cDNA and PCR reactions were performed as previously described (33). The primer sequences for the target genes and thermal cycling conditions are given in Table I. Densitometric analysis was performed using Scion Image with data from three independent experiments.

Statistical analysis. Statistical significance was determined using the Student's t-test on Microsoft Office Excel 2010 (Microsoft, Albuquerque, NM, USA) and results are presented as mean $\pm \mathrm{SD}$. $\mathrm{P}<0.05$ were considered statistically significant.

\section{Results}

Arctigenin inhibits cell migration and invasion of human breast cancer cells. The effects of arctigenin against metastasis were assessed by the ability of the cells to move and close the gap after creating uniform wounds with a $200 \mu \mathrm{l}$ pipette in the wound healing assay. Since MCF-7 cells are non-invasive ER-positive breast cancer cells, representing the ER/PR-positive luminal subtype, they were stimulated with the tumor promoter TPA to induce cell migration. However, treatment of TPA was omitted in MDA-MB-231 cells due to their inherent invasive properties. Our results show that arctigenin inhibited cell migration in both cell types. ER-positive MCF-7 control cells showed almost no cell migration. On TPA treatment, however, cell migration and almost complete wound closure were observed within $24 \mathrm{~h}$ (Fig. 2A). This TPA-induced cell migration was inhibited by arctigenin in a dose-dependent manner; exerting almost $90 \%$ inhibition of cell migration with $200 \mu \mathrm{M}$ arctigenin treatment (Fig. 2B). MDA-MB-231 cells exhibited high migratory characteristics, showing rapid wound closure, even in the control cells (Fig. 3A). However, similar to the effect of artigenin on MCF-7 cells, arctigenin inhibited the cell migration of MDA-MB-231 cells in a dose-dependent manner (Fig. 3B). The ability of cancer cells to invade and move across matrices were also evaluated using the Matrigel invasion assay. Arctigenin inhibited the TPA-induced invasive characteristics of MCF-7 cells (Fig. 2C) as well as the innate invasiveness of MDA-MB-231 cells (Fig. 3C) in a dosedependent manner. Thus, our data suggested that arctigenin inhibited cell migration and invasion of human breast cancer cells regardless of the presence of ER.

Arctigenin inhibits the crucial proteolytic enzyme MMP-9. For the cancer cells to metastasize, it has to first cross the physical barriers, i.e. the basement membrane and extracellular matrix. This is made possible by several protease enzymes, primarily the matrix metalloproteases (MMPs) that are capable of disrupting the extracellular matrix. The gelatinase MMP-9 is a highly regulated enzyme that is upregulated in the case of invasive breast cancers (34). Therefore, we looked at the effect of arctigenin on MMP-9, at both the activity and transcriptional levels. Since the synthesis and secretion of MMP-9 are induced by a variety of stimuli, including cytokines and TPA, both cell lines were treated with $100 \mathrm{nM}$ TPA for $24 \mathrm{~h}$ to induce detectable levels of MMP-9. First, we measured the activity of secreted MMP-9 in the conditioned media using zymography. 
A

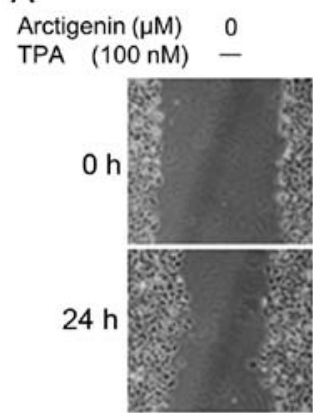

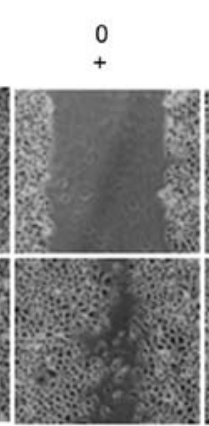
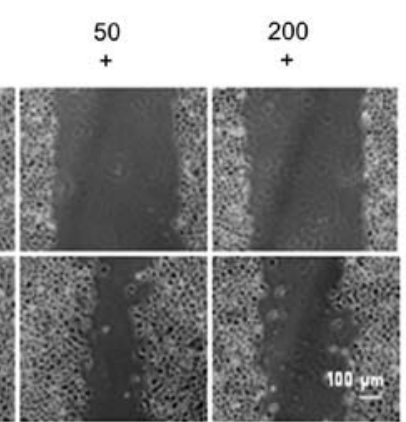

C

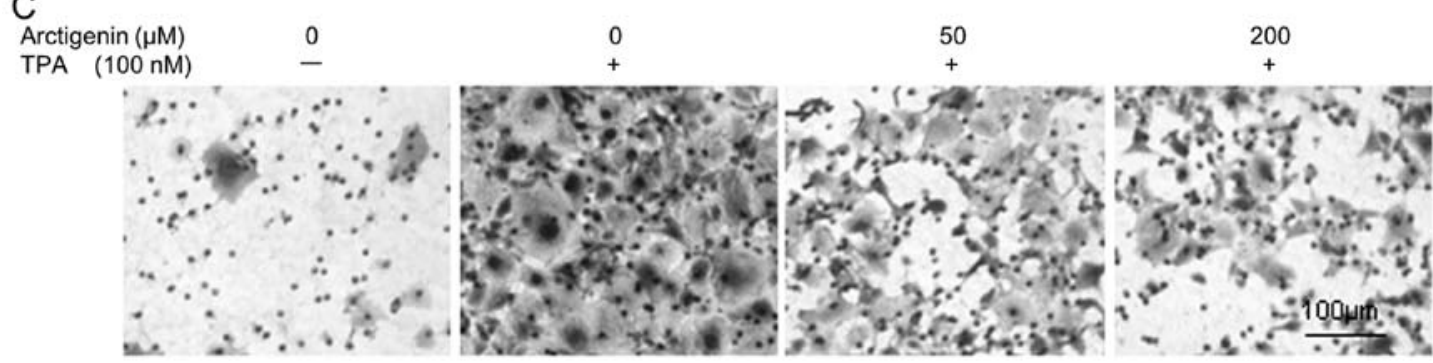

Figure 2. Arctigenin inhibits cell migration in ER-positive human breast cancer cell lines. (A) Optical microscopic images of TPA-induced wound healing in ER-positive MCF-7 human breast cancer cells 0 and $24 \mathrm{~h}$ after the creation of the wound. (B) Quantification of cell migration confirmed that $100 \mathrm{nM}$ TPA induced cell migration in MCF-7 cells which was significantly inhibited by $200 \mu \mathrm{M}$ arctigenin. (C) Optical microscopic images of invaded cells after invasion assay confirmed that arctigenin inhibites TPA-induced cell invasiveness of MCF-7 cells. Graphs represent the mean \pm SD of two independent experiments done in duplicate wells and images captured from two different areas of each well $(\mathrm{n}=8)$. P-values were calculated with respect to TPA treated controls. ${ }^{*} \mathrm{P}<0.05$ and ${ }^{* *} \mathrm{P}<0.01$

A

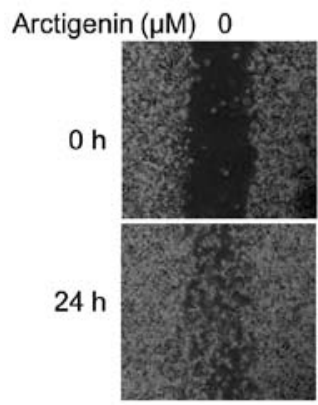

10
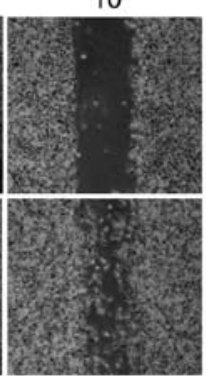

50

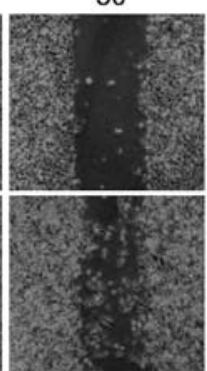

200

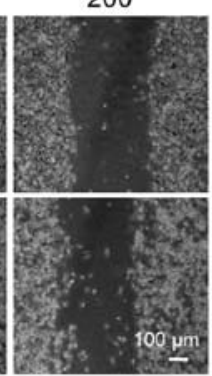

B

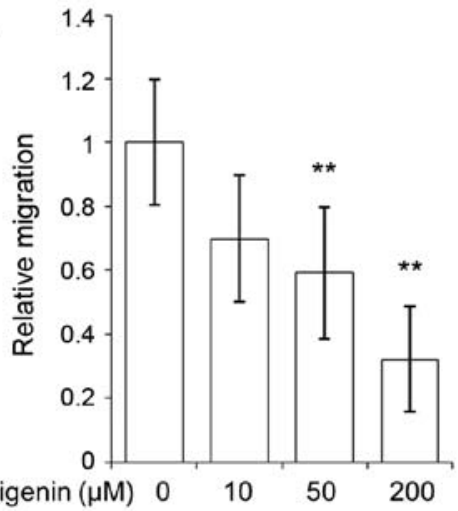

C

Arctigenin $(\mu \mathrm{M})$

10

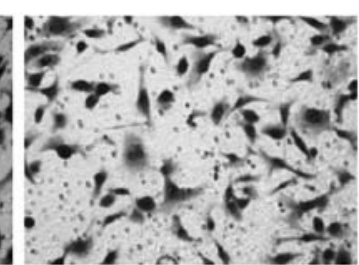

50

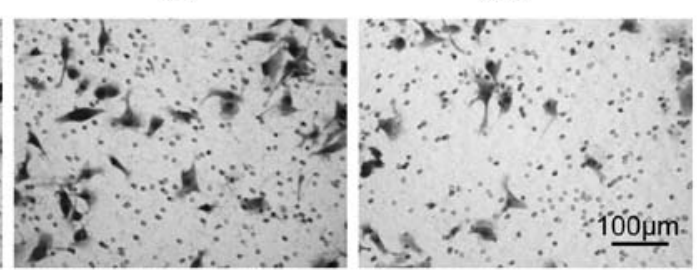

Figure 3. Arctigenin inhibits cell migration in ER-negative MDA-MB-231 human breast cancer cells. (A) Optical microscopic images of wound healing in ER-negative MDA-MB-231 human breast cancer cells. (B) Quantification of cell migration shows that arctigenin significantly inhibited cell migration in MDA-MB-231 cells. (C) Optical microscopic images of invaded cells after invasion assay confirm that arctigenin inhibits innate invasive characteristics of MDA-MB-231 cells. Graphs represent the mean \pm SD of two independent experiments done in duplicate wells and images captured from two different areas of each well $(\mathrm{n}=8)$. P-values were calculated with respect to controls without TPA. ${ }^{* *} \mathrm{P}<0.01$.

The collected media after $24 \mathrm{~h}$ treatment with various doses of arctigenin was run on SDS-PAGE gels containing $0.1 \%$ gelatin and the gelatinolytic activity could be quantified from the clear bands due to proteolysis after staining the gel with Coomassie 
A
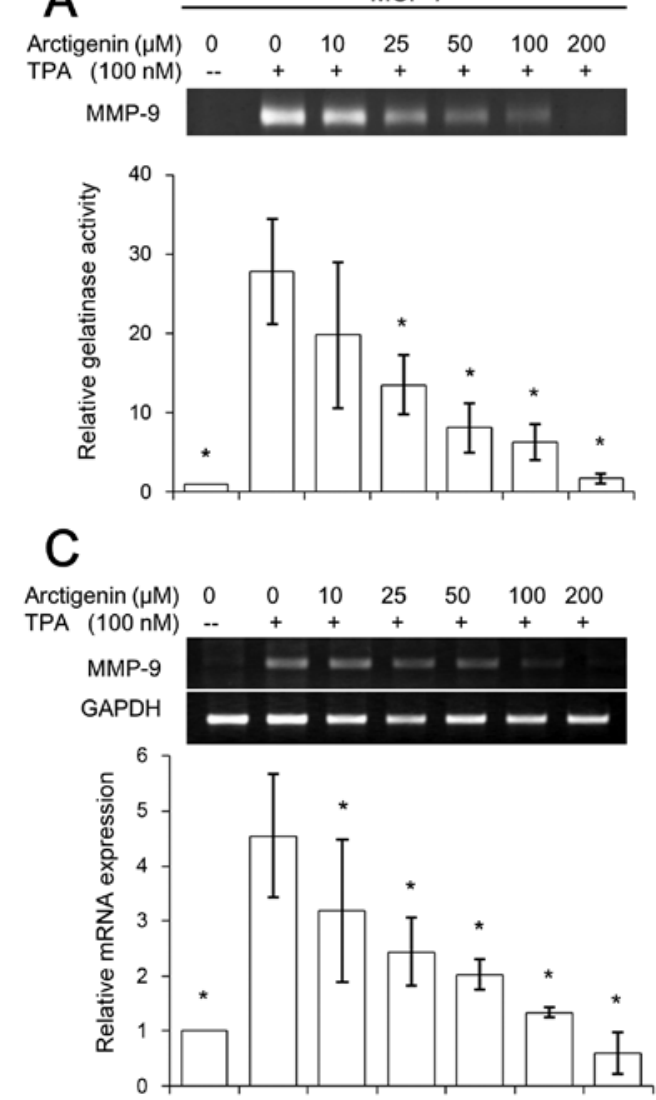

B

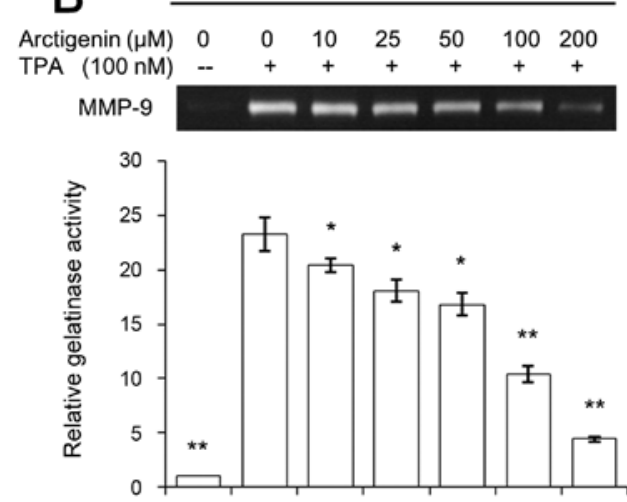

D

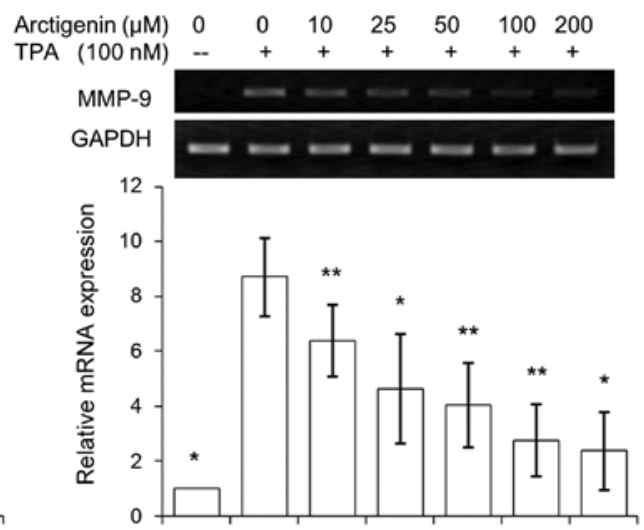

Figure 4. Arctigenin inhibits MMP-9 mRNA expression and activity. Twenty-four hours of TPA treatment induced MMP-9 mRNA expression as well as the activity in both MCF-7 and MDA-MB-231 human breast cancer cells, which were significantly inhibited by arctigenin. The gelatinase activities of MMP-9 in (A) MCF-7 and (B) MDA-MB-231 were analyzed by zymography and the mRNA expression was quantified using RT-PCR in (C) MCF-7 and (D) MDA-MB-231. The relative intensity of each sample was expressed as fold change compared with the TPA untreated control, after normalizing with respective loading control. Graphs represent the mean \pm SD of three independent experiments. ${ }^{*} \mathrm{P}<0.05$ and ${ }^{* *} \mathrm{P}<0.01$. P-values were calculated with respect to TPA treated controls.

brilliant blue. The endogenous level of MMP-9 activities were barely detectable in MCF-7 or MDA-MB-231 cells, while TPA treatment amplified MMP-9 activity 20 times in both MCF-7 (Fig. 4A) and MDA-MB-231 (Fig. 4B) cell lines. However, arctigenin exerted a dose-dependent inhibitory effect in both cell lines, exhibiting almost complete inhibition at $200 \mu \mathrm{M}$ arctigenin treatment (Fig. 4A and B). The gene expression of MMP-9 at the transcription level was also studied using RT-PCR. TPA treatment amplified MMP-9 mRNA levels $~ 3$ times in both MCF-7 (Fig. 4C) and MDA-MB-231 (Fig. 4D) cell lines. Similar to the effect of arctigenin on MMP-9 activity, the treatment with arctigenin showed a clear inhibitory effect on the expression of MMP-9 gene; in particular, the cells treated with conditioned media containing $200 \mu \mathrm{M}$ arctigenin showed almost basal level expression of MMP-9 in both cell lines (Fig. 4C and D). Therefore, our data suggested that arctigenin inhibited cell migration of human breast cancer cells by regulating the activity of MMP-9 and its gene expression regardless of the ER status.

Arctigenin suppressed the expression of $u P A$. It is well known that the activation of MMP-9 is mediated by the active serine protease urokinase-type plasminogen activator (uPA) and its receptor, uPAR (35). The cleavage of plasminogen to generate active plasmin was catalyzed by uPA/uPAR, which facilitates the release of several proteolytic enzymes, including MMPs. Thus, we tested whether the inhibitory effects of arctigenin on MMP-9 enzyme results from the suppressed expression of UPA and UPAR. TPA significantly induced both uPA and uPAR expressions in MCF-7 cells (Fig. 5A and C), while the endogenous levels in invasive MDA-MB-231 cells were relatively high (Fig. 5B and D) and the effect of TPA in inducing UPA and UPAR expression was very mild compared with MCF-7 cells. However, both cell lines showed that the expression of uPA was inhibited by high concentrations of arctigenin (Fig. 5A and B), whereas the UPAR levels remained unchanged (Fig. 5C and D).

Arctigenin inhibits TPA-induced Akt/NF- $\kappa B$ and MAPK signaling in MCF-7 human breast cancer cells. Our data so far showed that arctigenin inhibited cell migration in human breast cancer cells by inhibiting MMP-9 and uPA. The expression of MMP-9 and uPA can be modulated by various intracellular upstream signaling cascades, particularly the PI3K/Akt pathway and MAPK pathways (36). The activation of protein kinase $\mathrm{C}$ (PKC) by TPA induces the activation of two transcription factors, NF- $\mathrm{B}$ and AP-1; of which, activations are regulated by the PI3K/Akt and MAPK pathways. To understand the mechanism underlying the suppression of MMP-9 and uPA by arctigenin, we examined whether 

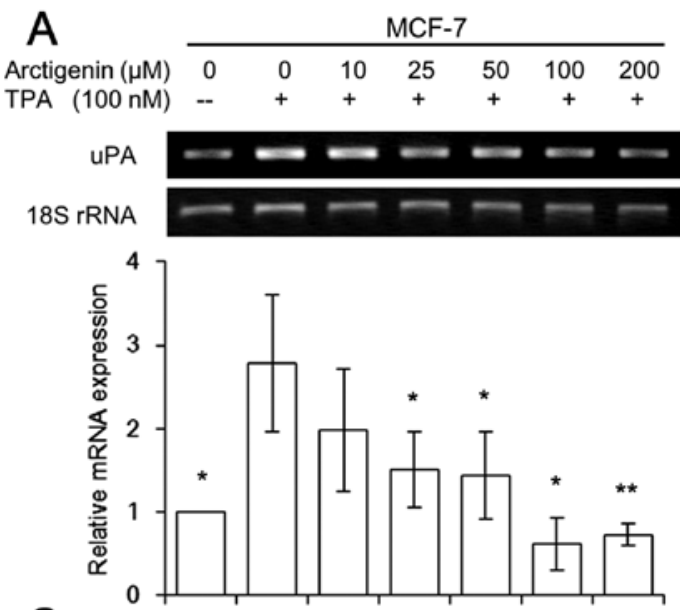

\section{$\mathrm{C}$}
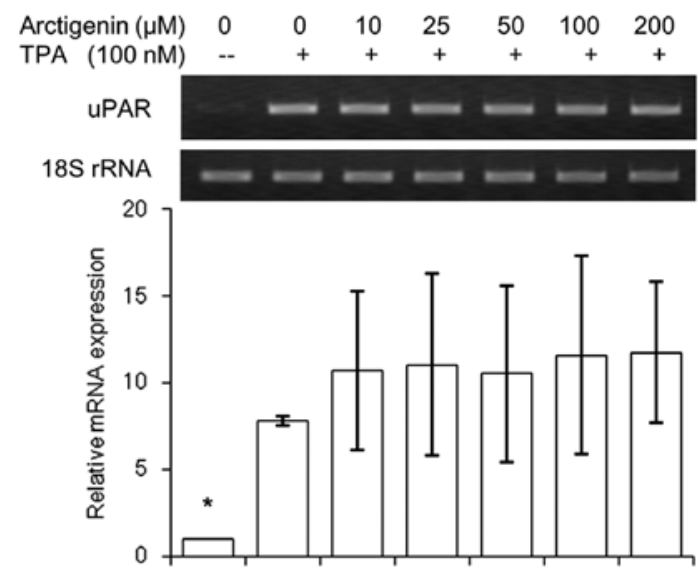

B

\begin{tabular}{|c|c|c|c|c|}
\hline & \multicolumn{4}{|c|}{ IVIDA-IVIB- $\angle 3 \mid$} \\
\hline enin $(\mu \mathrm{M})$ & 0 & 10 & 25 & \\
\hline
\end{tabular}

UPA

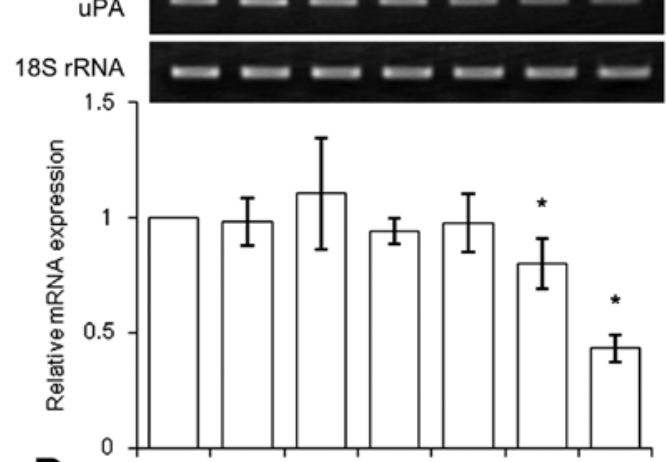

D
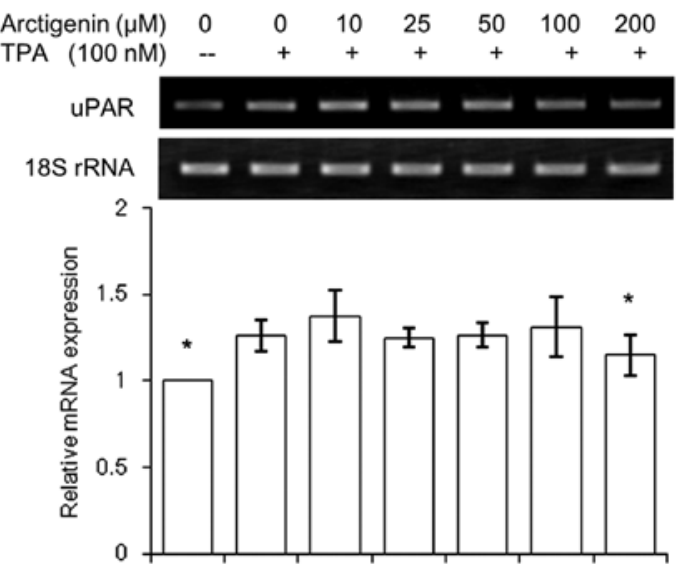

Figure 5. Effect of arctigenin on uPA/uPAR. The serine protease uPA was induced by TPA in (A) MCF-7 but not in (B) invasive MDA-MB-231 cells. uPA was slightly inhibited by high concentrations of arctigenin. The receptor uPAR was induced by TPA in both (C) MCF-7 and (D) MDA-MB-231 but the inhibitory effect of arctigenin on uPAR was not observed. mRNA expression was quantified using RT-PCR and the relative intensity of each sample was expressed as fold change compared with the TPA untreated control, after normalizing with respective loading control. Graphs represent the mean \pm SD of three independent experiments and ${ }^{*} \mathrm{P}<0.05$. P-values were calculated with respect to TPA treated controls. $\mathrm{P}<0.05$ and ${ }^{* *} \mathrm{P}<0.01$.

the treatment with arctigenin alter the PI3K/Akt and MAPK pathways. Since Akt activates the $N F-\kappa B$ transcription factor that translocates into the nucleus and initiates the transcription of MMP-9 and uPA, we first tested the inhibitory effect of arctigenin on the phosphorylation of Akt and NF- $\kappa \mathrm{B}$. As shown in Fig. 6A, the activated/phosphorylated forms of both Akt and NF- $\mathrm{B}$, which increased with the TPA treatment, were efficiently inhibited by arctigenin.

The MAPK pathway consists of the ERK 1/2, JNK $1 / 2$ and p38 signaling pathways. Its activation leads to the translocation of c-fos and c-jun into the nucleus to form the transcription factor AP-1, resulting in increased transcription of $\mathrm{UPA}$ and MMP-9. As shown in Fig. 6B, the phosphorylation of ERK 1/2 and JNK $1 / 2$ was significantly attenuated by arctigenin treatment in a dose-dependent manner, subsequently leading to a decrease in the expression of c-fos and c-jun. However, the phosphorylation of p38 was not altered by the treatment with arctigenin, suggesting that AP-1 transcription activity is suppressed by arctigenin through ERK 1/2 and JNK 1/2 MAPK pathways, rather than through p38 MAPK pathway.

Taken together, our data suggested that the inhibitory effect of arctigenin on MMP-9 and UPA appears to be mediated through the inhibition of AP-1 and NF- $\kappa$ B activity, via suppressing the phosphorylation of Akt, ERK 1/2 and JNK 1/2 (Fig. 7).

\section{Discussion}

According to their chemical structures, phytoestrogens are classified into isoflavones and lignans. Isoflavones are major constituents in soy products while lignans are widely distributed in fruits and vegetables. Arctigenin is a lignan phytoestrogen extracted from greater burdock and is consumed worldwide as foods and beverages. It is also used in traditional medicines for its health benefits. Several scientific studies report the beneficial effects of arctigenin and these include anti-oxidant, anti-inflammatory and antitumor activities. It has been shown that arctigenin inhibits the growth of various cancer cells by inhibiting the mitochondrial respiration (18), induction of apoptosis $(11,14,16,20-22)$ and cell cycle arrest (11,19-21). Studies also show that it kills cancer cells, specifically while sparing the normal cells (37). However, the effect of arctigenin on breast cancer cells has not been fully understood, although arctigenin, as a phytoestrogen, has been reported to have estrogenic properties. Recent studies reported that arctigenin possesses anticancer effect 
A

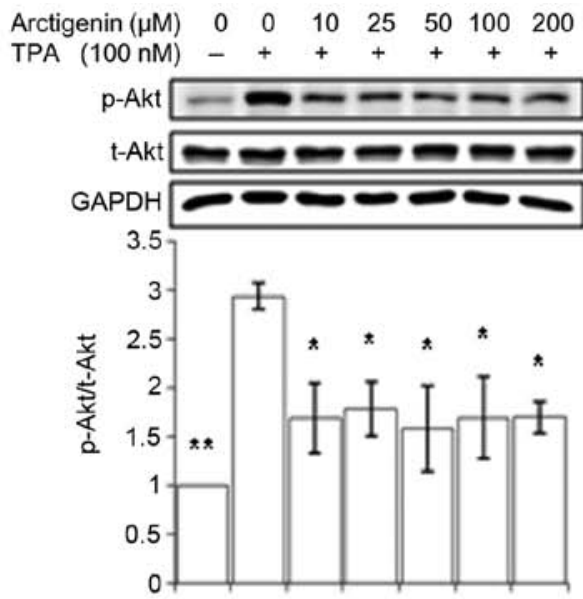

$\begin{array}{lllllll}0 & 0 & 10 & 25 & 50 & 100 & 200\end{array}$

$\mathrm{p}-\mathrm{NF}-\mathrm{KB} \square-\mathrm{m}-\mathrm{m}-\mathrm{m}$

$\mathrm{t}-\mathrm{NF}-\mathrm{KB} \longrightarrow-\infty-\infty-\infty$

GAPDH $=-\infty-\infty$

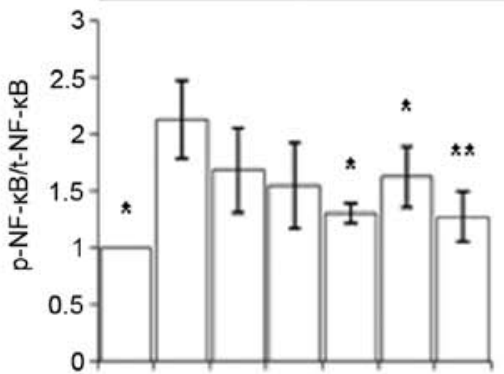

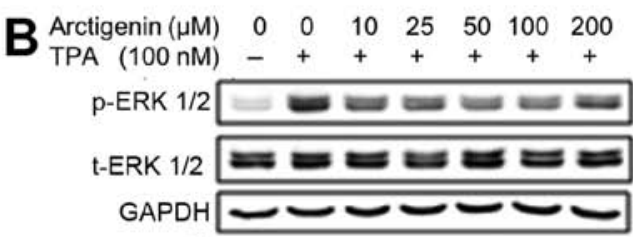

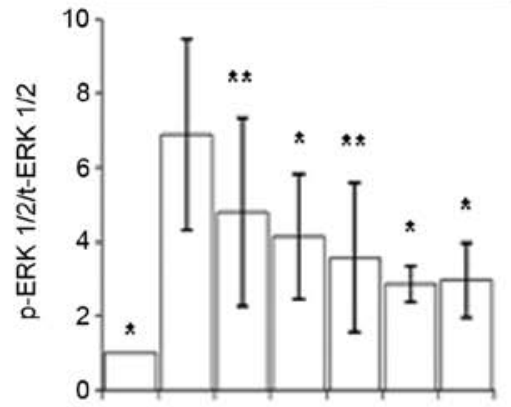

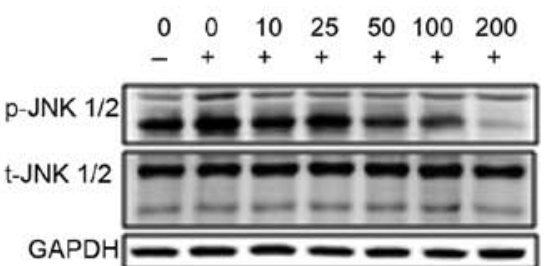

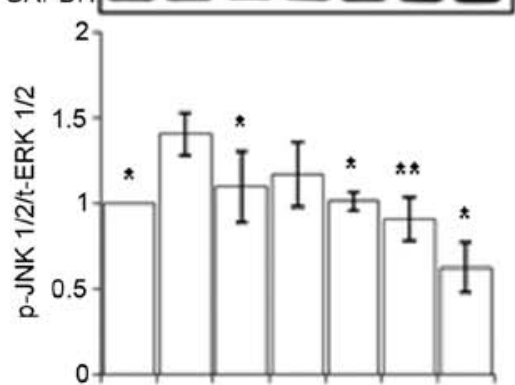

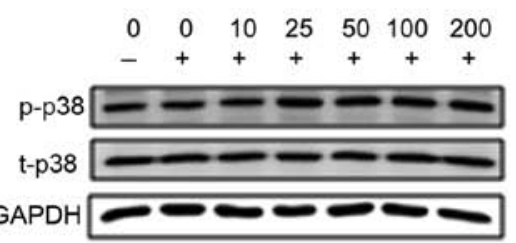

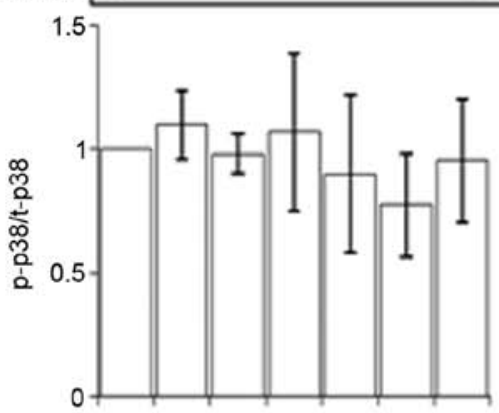

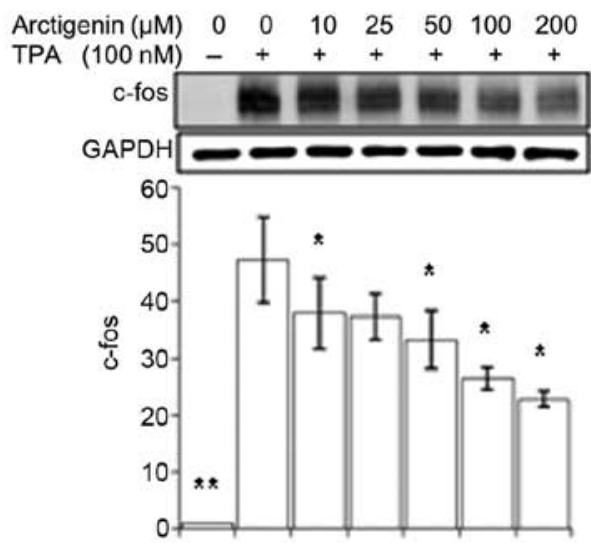

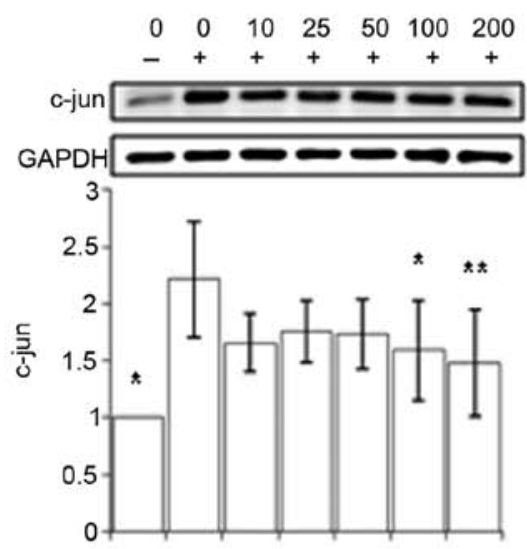

Figure 6. Arctigenin inhibited the major MMP-9 regulatory pathways Akt/NF- $\mathrm{kB}$ and MAPK/AP-1 in MCF-7 human breast cancer cell lines. Western blotting studies showed that $1 \mathrm{~h}$ of TPA treatment activated the MMP-9 regulators (A) Akt/NF- $\mathrm{kB}$ and (B) MAPK/AP-1. This TPA-induced phosphorylation of Akt and NF-KB was inhibited by arctigenin in a concentration-dependent manner. The MAPKs ERK 1/2 and JNK 1/2 activated by TPA were also inhibited by arctigenin, thereby inhibiting downstream c-fos and c-jun and the formation of AP-1 complex. The MAPK p38 was found to be unaffected. Graphs represent the mean \pm SD of three experiments and ${ }^{*} \mathrm{P}<0.05$ and ${ }^{* *} \mathrm{P}<0.01$. P-values were calculated with respect to TPA treated controls.

on ER-negative MDA-MB-231 cells by the mitochondrial caspase-independent apoptotic pathway (22). However, they observed that arctigenin showed neither a proliferative nor an anti-proliferative effects on ER-positive MCF-7 cells, suggesting that the antitumor effect of arctigenin may not be related to the ER signaling pathway.
In the present study, we demonstrated that arctigenin confers anti-metastatic effects on human breast cancer cells regardless of the presence of ER. Arctigenin efficiently inhibited cell migration in highly invasive MDA-MB-231 cells and also the TPA-induced cell migration in MCF-7 cells. This inhibition was shown to be dose-dependent, with 


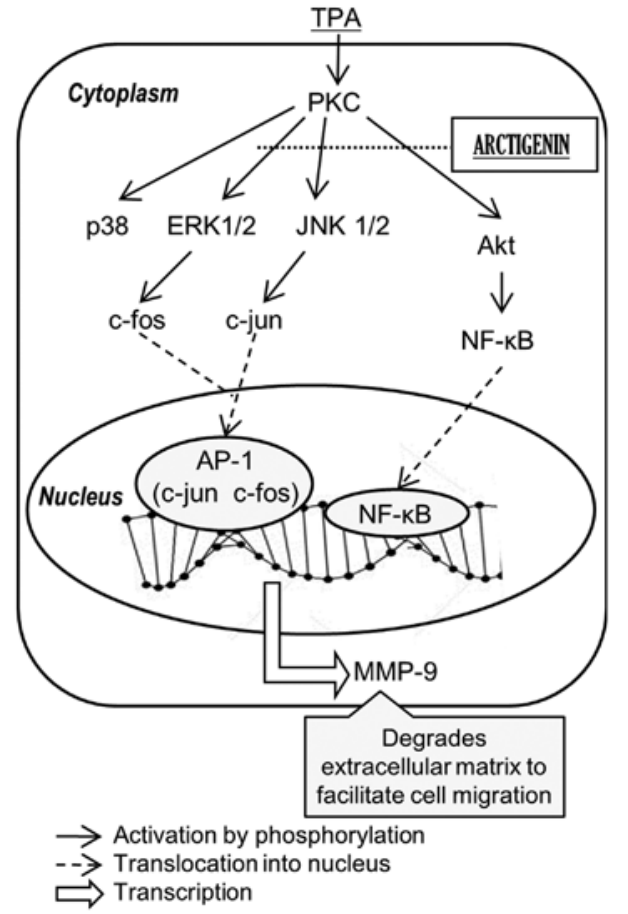

Figure 7. Proposed action mechanism of arctigenin for the inhibition of metastasis in human breast cancer cells. Arctigenin inhibited the two main regulatory pathways for MMP-9 expression, the MAPK/AP-1 and Akt/NF- $\mathrm{B}$ pathways. This inhibited downstream MMP-9 synthesis at the transcription level, and a decreased proteolytic activity led to the impairment of cell migration.

as little as $10 \mu \mathrm{M}$ arctigenin exerting significant inhibition and complete inhibition with $200 \mu \mathrm{M}$ arctigenin. This is in accordance with the anti-migratory capacity of arctigenin previously reported by Zhang et al (15), where $5 \mu \mathrm{M}$ arctigenin was found to inhibit cell migration in human colon cancer cell lines.

Cell migration and invasion are complex cellular behaviors that require coordination of many signaling pathways. However, critical proteolytic events must occur early in the metastatic cascade for the degradation of the basement membrane and successful intravasation. Almost all cells in tumor and host environment overexpress one or more of the proteolytic enzymes required for this purpose.

MMPs are a family of zinc- and calcium-dependent endoproteinases that are divided into four subclasses based on their substrate; collagenase, gelatinase, stromelysin and membrane-associated MMPs. MMP-2 and MMP-9 are the key enzymes due to their ability to degrade type IV collagen which is a major component of the basement membrane. It has been reported that the induction of MMP-9, also known as gelatinase-B and 92-kDa type IV collagenase, is particularly important for the invasiveness of human cancers, including breast cancer (38). Therefore, a blockade of MMP-9-mediated invasion suppresses the metastasis of breast cancer cells to the other organs. Synthesis and secretion of MMP-9 can be stimulated by a variety of growth factors and inflammatory cytokines during pathological processes and by agents, such as the tumor promoter TPA. The activation of MMP-9 is mediated by active serine protease UPA and UPAR $(35,39)$. The cleavage of plasminogen to generate active plasmin is catalyzed by
uPA/uPAR, which facilitates the release of several proteolytic enzymes, including MMPs.

Our data show that arctigenin decreased MMP-9 at the transcriptional level with a corresponding suppression in its activity level, which was observed with gelatinase zymography. The other metastatic protease uPA was also inhibited by arctigenin, whereas the UPAR levels remained unchanged. Zhang et al (15) have previously reported the inhibition of cell migration and invasion via the $\mathrm{Wnt} / \beta$-catenin pathway in human colon cancer cells. They also showed that arctigenin inhibited MMP-9 along with MMP-2. The activity of MMP-9 in various tumor cells is tightly controlled, with regulation occurring primarily at the transcription level. The promoter of human MMP-9 contains cis-acting regulatory elements that bind with transcription factors such as nuclear factor-kappa $\mathrm{B}$ (NF- $\mathrm{kB}$ ) or activator protein-1 (AP-1) (36). NF- $\mathrm{\kappa B}$ and AP-1 are ubiquitous eukaryotic transcription factors that can be induced by multiple stimuli. NF- $\mathrm{KB}$, a heterodimer of p50 and $\mathrm{p} 65$, is sequestered in the cytoplasm under normal conditions due to its association with the inhibitory protein, I $\mathrm{KB} \alpha$. Stimulation by inflammatory cytokines or tumor promoters leads to the dissociation of I $\mathrm{I} B \alpha$ from NF- $\kappa \mathrm{B}$ and the activated $\mathrm{NF}-\mathrm{\kappa B}$ translocates into the nucleus, binding to the promoter region of $M M P-9$ and leading to gene expression. AP-1 is a nuclear transcription factor that is comprised of homodimers and heterodimers of the members of the Fos and Jun family proteins. NF- $\kappa$ B and AP-1 dependent MMP-9 expression is regulated by Akt and MAPKs, respectively. In this study, we proved that arctigenin can inhibit metastasis of breast cancer cells through these pathways (Fig. 7). The activated Akt and NF- $\mathrm{KB}$, within $1 \mathrm{~h}$ of TPA treatment, was significantly inhibited by arctigenin. Furthermore, the phosphorylation of ERK $1 / 2$ and JNK $1 / 2$ were significantly attenuated by the treatment with arctigenin in a dose-dependent manner, which subsequently led to a decrease in the expression of c-fos and c-jun. However, the phosphorylation of p38 was not altered by the treatment with arctigenin. Although TPA is known to activate all three MAPKs i.e. ERK 1/2, JNK1/2 and p38, several studies showed that the activation of $\mathrm{p} 38$ depends on concentration or time-points of TPA treatment or cell lines $(40,41)$. Since activation of $\mathrm{p} 38$ was not observed in this study, we presumed that TPA treatment for $24 \mathrm{~h}$ was unable to induce $\mathrm{p} 38$ signaling in MCF-7 human breast cancer cells. This suggests that the AP-1 transcription activity is suppressed by arctigenin through ERK $1 / 2$ and JNK 1/2 MAPK pathways, rather than through the p38 MAPK pathway.

Taken together, these data suggest that arctigenin confers anti-metastatic effects by inhibiting MMP-9 and uPA via the Akt, NF-kB and MAPK signaling pathways on breast cancers, regardless of ER expression. Therefore, we propose that consumption of burdock tea and arctigenin-enriched food products maybe a safe supplement for breast cancer patients in preventing metastasis.

\section{Acknowledgements}

The present study was supported by the Basic Science Research Program through the National Research Foundation of Korea (NRF) funded by the Ministry of Education (2015R1D1A1A01058841). 


\section{References}

1. Gao H, Li G, Zhang J and Zeng J: Arctigenin: A lignan from Arctium lappa. Acta Crystallogr Sect E Struct Rep Online 64: o1538, 2008.

2. Kim Y, Hollenbaugh JA, Kim DH and Kim B: Novel PI3K/Akt inhibitors screened by the cytoprotective function of human immunodeficiency virus type 1 Tat. PLoS One 6: e21781, 2011.

3. Hayashi K, Narutaki K, Nagaoka Y, Hayashi T and Uesato S Therapeutic effect of arctiin and arctigenin in immunocompetent and immunocompromised mice infected with influenza A virus. Biol Pharm Bull 33: 1199-1205, 2010.

4. Swarup V, Ghosh J, Mishra MK and Basu A: Novel strategy for treatment of Japanese encephalitis using arctigenin, a plant lignan. J Antimicrob Chemother 61: 679-688, 2008.

5. Lee JY and Kim CJ: Arctigenin, a phenylpropanoid dibenzylbutyrolactone lignan, inhibits type I-IV allergic inflammation and pro-inflammatory enzymes. Arch Pharm Res 33: 947-957, 2010.

6. Kang HS, Lee JY and Kim CJ: Anti-inflammatory activity of arctigenin from Forsythiae Fructus. J Ethnopharmacol 116 305-312, 2008

7. Yao X, Li G, Lü C, Xu H and Yin Z: Arctigenin promotes degradation of inducible nitric oxide synthase through CHIPassociated proteasome pathway and suppresses its enzyme activity. Int Immunopharmacol 14: 138-144, 2012.

8. Tsai WJ, Chang CT, Wang GJ, Lee TH, Chang SF, Lu SC and Kuo YC: Arctigenin from Arctium lappa inhibits interleukin-2 and interferon gene expression in primary human $\mathrm{T}$ lymphocytes. Chin Med 6: 12, 2011.

9. Cho MK, Park JW, Jang YP, Kim YC and Kim SG: Potent inhibition of lipopolysaccharide-inducible nitric oxide synthase expression by dibenzylbutyrolactone lignans through inhibition of I-kappaBalpha phosphorylation and of p65 nuclear translocation in macrophages. Int Immunopharmacol 2: 105-116, 2002.

10. Cho MK, Jang YP, Kim YC and Kim SG: Arctigenin, a phenylpropanoid dibenzylbutyrolactone lignan, inhibits MAP kinases and AP-1 activation via potent MKK inhibition: The role in TNF-alpha inhibition. Int Immunopharmacol 4: 1419-1429, 2004

11. Jeong JB, Hong SC, Jeong HJ and Koo JS: Arctigenin induces cell cycle arrest by blocking the phosphorylation of $\mathrm{Rb}$ via the modulation of cell cycle regulatory proteins in human gastric cancer cells. Int Immunopharmacol 11: 1573-1577, 2011.

12. Susanti S, Iwasaki H, Itokazu Y, Nago M, Taira N, Saitoh S and Oku H: Tumor specific cytotoxicity of arctigenin isolated from herbal plant Arctium lappa L. J Nat Med 66: 614-621, 2012.

13. Awale S, Lu J, Kalauni SK, Kurashima Y, Tezuka Y, Kadota S and Esumi H: Identification of arctigenin as an antitumor agent having the ability to eliminate the tolerance of cancer cells to nutrient starvation. Cancer Res 66: 1751-1757, 2006.

14. Kim JY, Hwang JH, Cha MR, Yoon MY, Son ES, Tomida A, Ko B, Song SW, Shin-ya K, Hwang YI, et al: Arctigenin blocks the unfolded protein response and shows therapeutic antitumor activity. J Cell Physiol 224: 33-40, 2010.

15. Zhang S, Li J, Song S, Li J, Tong R, Zang Z, Jiang Q and Cai L Integrated in silico and experimental methods revealed that Arctigenin inhibited angiogenesis and HCT116 cell migration and invasion through regulating the $\mathrm{H} 1 \mathrm{~F} 4 \mathrm{~A}$ and $\mathrm{Wnt} / \beta$-catenin pathway. Mol Biosyst 11: 2878-2884, 2015.

16. Hausott B, Greger H and Marian B: Naturally occurring lignans efficiently induce apoptosis in colorectal tumor cells. J Cancer Res Clin Oncol 129: 569-576, 2003.

17. Gu Y, Scheuer C, Feng D, Menger MD and Laschke MW: Inhibition of angiogenesis: A novel antitumor mechanism of the herbal compound arctigenin. Anticancer Drugs 24: 781-791, 2013.

18. Gu Y, Qi C, Sun X, Ma X, Zhang H, Hu L, Yuan J and Yu Q: Arctigenin preferentially induces tumor cell death under glucose deprivation by inhibiting cellular energy metabolism. Biochem Pharmacol 84: 468-476, 2012.

19. Susanti S, Iwasaki H, Inafuku M, Taira $\mathrm{N}$ and Oku H: Mechanism of arctigenin-mediated specific cytotoxicity against human lung adenocarcinoma cell lines. Phytomedicine 21: 39-46, 2013.

20. Yang S, Ma J, Xiao J, Lv X, Li X, Yang H, Liu Y, Feng S and Zhang Y: Arctigenin anti-tumor activity in bladder cancer T24 cell line through induction of cell-cycle arrest and apoptosis. Anat Rec (Hoboken) 295: 1260-1266, 2012.
21. Huang K, Li LA, Meng YG, You YQ, Fu XY and Song L: Arctigenin promotes apoptosis in ovarian cancer cells via the iNOS/NO/STAT3/survivin signalling. Basic Clin Pharmacol Toxicol 115: 507-511, 2014

22. Hsieh CJ, Kuo PL, Hsu YC, Huang YF, Tsai EM and Hsu YL: Arctigenin, a dietary phytoestrogen, induces apoptosis of estrogen receptor-negative breast cancer cells through the ROS/ p38 MAPK pathway and epigenetic regulation. Free Radic Biol Med 67: 159-170, 2014.

23. Jin JS, Lee JH and Hattori M: Ligand binding affinities of arctigenin and its demethylated metabolites to estrogen receptor alpha. Molecules 18: 1122-1127, 2013.

24. Matsumura A, Ghosh A, Pope GS and Darbre PD: Comparative study of oestrogenic properties of eight phytoestrogens in MCF7 human breast cancer cells. J Steroid Biochem Mol Biol 94: 431-443, 2005.

25. Rice S and Whitehead SA: Phytoestrogens and breast cancer-promoters or protectors? Endocr Relat Cancer 13: 995-1015, 2006.

26. Lephart ED: Modulation of aromatase by phytoestrogens. Enzyme Res 2015: 594656, 2015. doi: 10.1155/2015/594656

27. Whitehead SA and Lacey M: Phytoestrogens inhibit aromatase but not 17beta-hydroxysteroid dehydrogenase (HSD) type 1 in human granulosa-luteal cells: Evidence for FSH induction of 17beta-HSD. Hum Reprod 18: 487-494, 2003

28. Low YL, Taylor JI, Grace PB, Dowsett M, Scollen S, Dunning AM, Mulligan AA, Welch AA, Luben RN, Khaw KT, et al: Phytoestrogen exposure correlation with plasma estradiol in postmenopausal women in European Prospective Investigation of Cancer and Nutrition-Norfolk may involve diet-gene interactions. Cancer Epidemiol Biomarkers Prev 14: 213-220, 2005.

29. DeSantis C, Ma J, Bryan L and Jemal A: Breast cancer statistics, 2013. CA Cancer J Clin 64: 52-62, 2014

30. Jung KW, Won YJ, Kong HJ, Oh CM, Seo HG and Lee JS: Cancer statistics in Korea: Incidence, mortality, survival and prevalence in 2010. Cancer Res Treat 45: 1-14, 2013.

31. Straatman K: Wound healing assay. University of Leicester, College of Medicine, Biological Sciences and Psychology, Advanced Imaging Facilities, 2008.

32. Loughlin DT and Artlett CM: Modification of collagen by 3-deoxyglucosone alters wound healing through differential regulation of p38 MAP kinase. PLoS One 6: e18676, 2011.

33. Lee K, Shin J, Kwon Y, Moon D and Nam K: Suppression of cancer progression and metastasis in HT-29 human colorectal adenocarcinomas by deep sea water. Biotechnol Bioprocess Eng 18: 194-200, 2013.

34. Mehner C, Hockla A, Miller E, Ran S, Radisky DC and Radisky ESR: Tumor cell-produced matrix metalloproteinase 9 (MMP-9) drives malignant progression and metastasis of basallike triple negative breast cancer. Oncotarget 5: 2736-2749, 2014

35. Holst-Hansen C, Johannessen B, Høyer-Hansen G, Rømer J, Ellis $\mathrm{V}$ and Brünner N: Urokinase-type plasminogen activation in three human breast cancer cell lines correlates with their in vitro invasiveness. Clin Exp Metastasis 14: 297-307, 1996.

36. Lungu G, Covaleda L, Mendes O, Martini-Stoica H and Stoica G: FGF-1-induced matrix metalloproteinase-9 expression in breast cancer cells is mediated by increased activities of NF-kappaB and activating protein-1. Mol Carcinog 47: 424-435, 2008.

37. Moritani S, Nomura M, Takeda Y and Miyamoto K: Cytotoxic components of bardanae fructus (goboshi). Biol Pharm Bull 19: 1515-1517, 1996

38. McCawley LJ and Matrisian LM: Matrix metalloproteinases: Multifunctional contributors to tumor progression. Mol Med Today 6: 149-156, 2000

39. Duffy MJ: The urokinase plasminogen activator system: Role in malignancy. Curr Pharm Des 10: 39-49, 2004.

40. Cheepala SB, Yin W, Syed Z, Gill JN, McMillian A, Kleiner HE, Lynch M, Loganantharaj R, Trutschl M, Cvek U, et al: Identification of the B-Raf/Mek/Erk MAP kinase pathway as a target for all-trans retinoic acid during skin cancer promotion. Mol Cancer 8: 27, 2009.

41. Lilleholt LL, Johansen C, Arthur JS, Funding A, Bibby BM, Kragballe $\mathrm{K}$ and Iversen L: Role of p38 mitogen-activated protein kinase isoforms in murine skin inflammation induced by 12-O-tetradecanoylphorbol 13-acetate. Acta Derm Venereol 91: 271-278, 2011. 